\title{
EXISTENCE AND CONCENTRATION OF GROUND STATE SOLUTION TO A CRITICAL $p$-LAPLACIAN EQUATION
}

\section{XUdONG SHANG AND JiHUi ZHANG}

Abstract. In this paper, we consider the existence and concentration behavior of positive ground state solution to the following problem

$$
\left\{\begin{array}{l}
-h^{p} \Delta_{p} u+V(x)|u|^{p-2} u=K(x)|u|^{q-2} u+|u|^{p^{*}-2} u, x \in \mathbb{R}^{N}, \\
u \in W^{1, p}\left(\mathbb{R}^{N}\right), u>0, x \in \mathbb{R}^{N},
\end{array}\right.
$$

where $h$ is a small positive parameter, $1<p<N, \max \left\{p, p^{*}-\frac{p}{p-1}\right\}<q<p^{*}, p^{*}=\frac{N p}{N-p}$ is the critical Sobolev exponent, $V(x)$ and $K(x)$ are positive smooth functions. Under some necessary restrictions, we show that for small $h>0$, the equation has a positive ground state solution. Furthermore, we establish the concentration property of such solutions when $h$ tends to zero.

Mathematics subject classification (2010): 35J92, 35J35.

Keywords and phrases: $p$-Laplacian, ground state, critical growth, positive solution.

\section{REFERENCES}

[1] J.G. Azorero, I.P. Alonso, Multiplicity of solutions for elliptic problems with critical exponent or with nonsymmetric term, Trans. Amer. Math. Soc. 323, 2 (1991), 877-895.

[2] A. Ambrosetti, M. Badiale, S. Cingolani, Semiclassical states of nonlinear Schrödinger equations, Arch. Rat. Mech. Anal., 140, 1 (1997), 285-300.

[3] C.O. Alves, G.M. Figueiredo, Existence and multiplicity of positive solutions to a $p$-Laplacian equation in $\mathbb{R}^{N}$, Differential Integral Equations Anal., 19 (2006), 143-162.

[4] C.O. Alves, G.M. FigueIRedo, On multiplicity and concentration of positive solutions for a class of quasilinear problems with critical exponential growth in $\mathbb{R}^{N}$, J. Differential Equations, 246 (2009), $1288-1311$.

[5] C.O. ALvEs, Existence and multiplicity of solution for a class of quasilinear equations, Adv. Nonlinear Studies, 5 (2005), 73-86.

[6] C.O. Alves, M. S. Souto, Existence of solutions for a class of nonlinear Schrödinger equations with potential vanishing at infinity, J. Differential Equations, 254 (2013), 1977-1991.

[7] J. BYEON, Z.Q. WANG, Standing waves with a critical frequency for nonlinear Schrödinger equations, Arch. Rational Mech. Anal. 165 (2002), 295-316.

[8] S. Cingolani, M. Lazzo, Multiple positive solutions to nonlinear Schrödinger equations with competing potential functions, J. Differential Equations, 160 (2000), 118-138.

[9] M. DEL PINO, P. Felmer, Semi-classical states of nonlinear Schrödinger equations: a variational reduction method, Math. Ann, 324 (2002), 1-32.

[10] Y. DING, F. LIN, Solutions of perturbed Schrödinger equations with critical nonlinearity, Calc. Var. PDE., 30 (2007), 231-249.

[11] J.M. DO Ó, On existence and concentration of positive bounded states of p-Laplacian equation in $\mathbb{R}^{N}$ involving critical growth, Nonlinear Anal., 62 (2005), 777-801.

[12] G.M. FigueIREDO, Multiplicity of solutions for a quasilinear problem with supercritical growth, Electronic Journal of Differ. Equ., 31 (2006), 1-7. 
[13] G.M. FIGUEIREDo, Existence, multiplicity and concentration of positive solutions for a class of quasilinear problems with critical growth, Communications on Applied Nonlinear Analysis, 4 (2006), 79 99.

[14] G.M. Figueiredo, M.F. Furtado, Positive solutions for a quasilinear Schrödinger equation with critical growth, J. Dyn. Diff. Equat., 24 (2012), 13-28.

[15] A. FlOER, A. WEINSTEIN, Nonspreading waves packets for the cubic Schrödinger equations with a bounded potential, J. Funct. Anal., 69 (1986), 397-408.

[16] M.W. FEI, H.C. YIN, Existence and concentration of bound states of nonlinear Schrödinger equations with compactly supported competing potentials, Pacific Journal of Mathematics, 244 (2010), 261-295.

[17] C.F. GUI, Existence of multi-bumps solutions for nonlinear Schrödinger equations via variational methods, Comm. Partial Differential Equations, (1996), 787-820.

[18] P.L. Lions, The concentration-compcatness principle in the calculus of variations. The limit case. Part I, Rev. Mat. Iber. 1, 2 (1985), 109-145.

[19] P.L. Lions, The concentration-compcatness principle in the calculus of variations. The locally compact case. Part II, Ann. Inst. H. Poincare Non Lineaire, 1 (1984), 223-283.

[20] L. JEANJEAN, K. TANAKA, Singularly perturbed elliptic problems with superlinear or asympotically linear nonlinearities, Calc. Var. PDE., 21 (2004), 287 - 318.

[21] Y.G. ОН, Existence of semiclassical bound states of nonlinear Schrödinger equations with potentials of the class(V), Comm. Partial Differential Equations, 13 (1988), 1499-1519.

[22] P.H. RABINOwitZ, On a class of nonlinear Schrödinger equations, Z. Angew. Math. Phys., 43 (1992), 270-291.

[23] J. SERRIN, Local behavior of solutions of quasilinear equations, Acta Math., 111 (1964), 247-302.

[24] P. TOLKSDORF, Regularity for a more general class of quasilinear elliptic equations, J. Differential Equations, 51 (1984), 126-150.

[25] M. Willem, Minimax Theorems, Birkhäuser, Bosten, 1996.

[26] X.F. WANG, B. ZENG, On concentration of positive bound states of nonlinear Schrödinger equations with competing potential functions, SIAM J. Math. Anal., 28 (1997), 633-655. 